\title{
Improvement of Power Factor and Harmonic Elimination in Distribution Line using PI with Hysteresis Current Controller
}

\author{
Narayan Nahak ${ }^{1}$, Mihir Narayan Mohanty ${ }^{2}$ \\ ${ }^{1}$ ITER, Siksha 'O' Anusadhan University ${ }^{2}$ ITER, Siksha 'O' Anusadhan University
}

\begin{abstract}
Power quality improvement is a major research area in current context. Though much work has been done by many researchers still scope is there to work on this area. In this paper an attempt is made to eliminate the harmonics as well as for the improvement of power factor. Here distribution static synchronous compensator (DSTATCOM) is used to improve power factor in distribution line \& mitigate harmonics with an optional feature of voltage regulation. Further the frequency analysis of the distribution line is analyzed both before \& after compensation. A relay based hysteresis current regulator is used for DSTATCOM controller in indirect current control technique. Simulation is carried out in standard MATLAB environment. Results of simulations are presented for linear \& nonlinear load.
\end{abstract}

Keywords : - Power factor, DSTATCOM, Harmonics, Distribution Line, PI

\section{INTRODUCTION}

In present scenario the compensation of reactive power and unbalance in load current has been a great challenge for power engineers. The adverse effects of low power factor and unbalance loads are increased losses and overloading of one particular phase. These problems are aggravated in harmonic environment, created by power electronics converters. These converters do not only corrupt the current but also distort the system voltage [1]. Moreover there is always some amount of voltage unbalance present in the distribution system. Advent of FACTS devices helps a lot to meet the requirements in power sector [3].Performance of DSTATCOM system depends on the algorithm used for its control circuit. There is various control algorithms used for detection of reference current for switching of VSC. Using Simulink's power system block set, simulation of DSTATCOM is done as [4].A control technique for Cascaded H-Bridge Converter based DSTATCOM is also performed as [5]. Overall, the control algorithm for DSTATCOM should be simple \& easy to implement and work well with non-sinusoidal and unbalanced ac mains.

A distribution static compensator or DSTATCOM can exchange both active and reactive power with the distribution system by varying the amplitude and phase angle of the converter voltage with respect to the line terminal voltage, if an energy storage system (ESS) is included into the dc bus[1]. It provides a controlled current flow through the tie reactance between the DSTATCOM and the distribution network. This enables the DSTATCOM to mitigate voltage fluctuations and to correct the power factor of weak distribution systems. Nowadays, there are an increasing number of non-linear loads which inject harmonics into the system. A threephase insulated gate bipolar transistor- (IGBT-) based current controlled voltage source inverter with a DC bus capacitor known as a DSTATCOM is used for power factor correction, harmonic compensation and for providing required reactive power to the load. Here the DSTATCOM employs an indirect current control technique [1] with a current regulator using relays \& logic circuit.

\section{METHODOLOGY}

Figure 2(a) below shows the basic diagram of a DSTATCOM connected to a distribution line. The three phase source supplies a linear/non linear load. The DSTATCOM system here has a three leg IGBT based voltage source converter bridge with the input ac inductors and a dc bus capacitor to obtain a self-supporting dc bus as shown in fig2(b). The output of the inverter is connected to the point of common coupling (PCC) using interface inductors [1]. DSTATCOM is connected in shunt configuration to the main ac network.

The DSTATCOM uses an indirect current control technique for generating appropriate switching sequence of the eight IGBT switches [1]. The control scheme utilizes two PI controllers. One PI controller is used for the regulation of DC link voltage and the second PI controller is used for the regulation of ac terminal voltage. DSTATCOM can be used for power-factor correction, voltage regulation and harmonic mitigation. Only one PI controller over the DC link is sufficient for providing power factor correction \& harmonic mitigation. But, voltage regulation requires an additional PI controller over ac terminal voltage which is an optional feature here. Both power factor correction \& voltage regulation cannot be achieved simultaneously [6]. The three-phase reference supply currents $\left(i_{\text {sar }}, i_{\text {sbr }} i_{\text {scr }}\right)$ are computed using three-phase ac voltages $\left(v_{t a}, v_{t b}, v_{t c}\right)$ 
and dc bus voltage (Vdc) of DSTATCOM. These reference supplies currents consist of two components, one inphase (Ispdr) and another in quadrature (Ispqr) with the supply voltages.

The three-phase quadrature unit current templates ( $w \mathrm{a}, w \mathrm{~b}$ and $w \mathrm{c})$ are derived from in-phase unit current templates $\left(u_{\mathrm{a}}, u_{\mathrm{b}}\right.$ and $\left.u_{\mathrm{c}}\right)$. The multiplication of in-phase amplitude with in-phase unit current templates results in the in-phase components (isadr, isbdr and iscdr) of three-phase reference supply currents and similarly multiplication of quadrature amplitude with quadrature unit current templates results in the quadrature components (isaqr, isbqr and iscqr) of three-phase reference supply currents. Algebraic sum of these in-phase and quadrature components results in the three-phase reference supply currents (isar, $i$ sbr and $i$ scr) as [1].

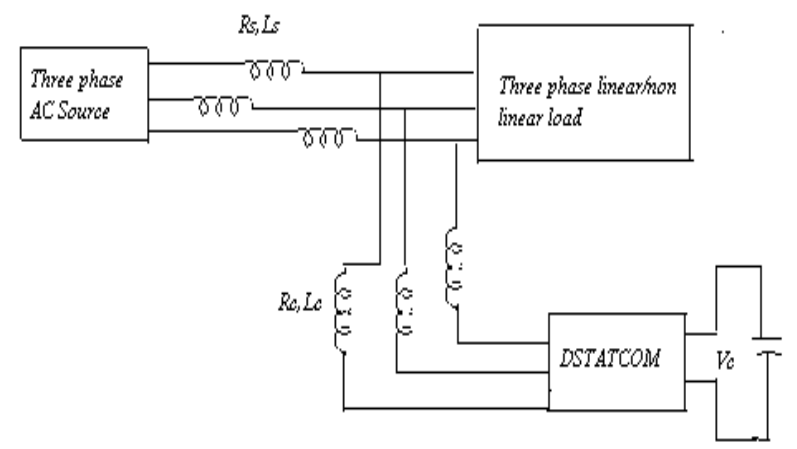

Fig2(a)

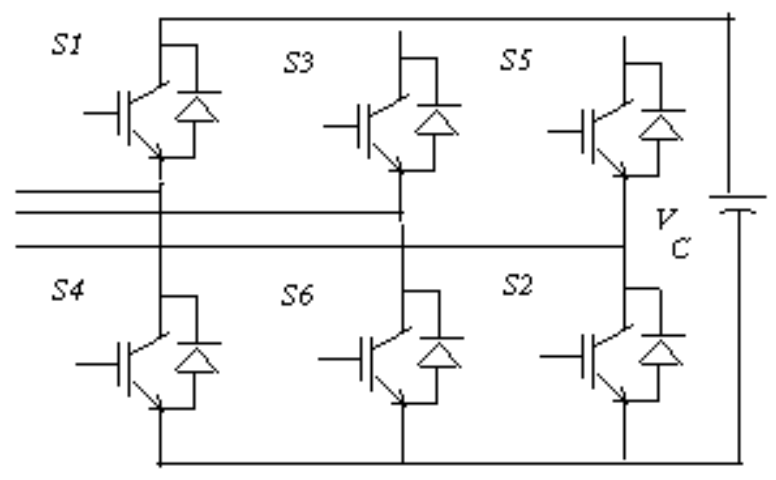

Fig2(b)

Figure 2(a) Block diagram representation of DSTATCOM connected to distribution line \&(b) The DSTATCOM realized by a IGBT based converter .

The DSTATCOM has IGBT switches which are controlled by a gate driver circuit employing an indirect current control technique associated with a relay based hysteresis current regulator.

\section{ANALYSIS OF CONTROL SCHEME FOR DSTATCOM}

The three-phase reference source currents are computed using three-phase AC voltages $\left(v_{t a}, v_{t b}\right.$ and $\left.v_{t c}\right)$ and DC bus voltage $\left(V_{d c}\right)$ of DSTATCOM. These reference supply currents consist of two components, one inphase $\left(I_{s p d r}\right)$ and another in quadrature $\left(I_{s p q r}\right)$ with the supply voltages. The basic equations of control algorithm of DSTATCOM are as follows:

\section{(i) Computation of in-phase components of reference supply current.}

The instantaneous values of in-phase component of reference supply currents $\left(I_{s p d r}\right)$ is computed using one PI controller over the average value of DC bus voltage of the DSTATCOM $\left(v_{d c}\right)$ and reference DC voltage $\left(v_{d c r}\right)$ as

$$
I_{s p d r}=I_{s p d r(n-1)}+K_{p d}\left\{v_{d e(n)}-v_{d e(n-1)}\right\}+K_{i d} v_{d e(n)}
$$

where $v_{d e(n)}=v_{d c r}-v_{d c a(n)}$ denote the error in $v_{d c r}$ and average value of $v_{d c}, K_{p d}$ and $K_{i d}$ are proportional and integral gains of the DC bus voltage PI controller.

The output of this PI controller $\left(I_{s p d r}\right)$ is taken as amplitude of in-phase component of the reference supply currents. Three-phase in-phase components of the reference supply currents $\left(i_{s a d r}, i_{s b d r}\right.$ and $\left.i_{s c d r}\right)$ are computed using the in-phase unit current vectors $\left(u_{a}, u_{b}\right.$ and $\left.u_{c}\right)$ derived from the AC terminal voltages $\left(v_{t a n}, v_{t b n}\right.$ and $v_{t c n}$ ), respectively.

$$
u_{a}=v_{t a} / V_{t m}, u_{b}=v_{t b} / V_{t m}, u_{c}=v_{t c} / V_{t m}
$$

Where $V_{\mathrm{tm}}$ is amplitude of the supply voltage and it is computed as 


$$
V_{t m}=\left[(2 / 3)\left(V_{\tan }^{2}+V_{t b n}^{2}+V_{t c n}^{2}\right)\right]^{1 / 2}
$$
computed as

The instantaneous values of in-phase component of reference supply currents $\left(i_{\text {sadr }}, i_{\text {sbdr }}\right.$ andi $\left.i_{\text {scdr }}\right)$ are

$$
\mathbf{i}_{\text {sadr }}=I_{\text {spdr }} \mathbf{u}_{\mathrm{a}}, \mathbf{i}_{\text {sbdr }}=\mathbf{I}_{\text {spdr }} \mathbf{u}_{\mathrm{b},} \mathbf{i}_{\text {scdr }}=\mathbf{I}_{\text {spdr }} \mathbf{u}_{\mathrm{c}}
$$

\section{(ii) Computation of quadrature components of reference supply current}

The amplitude of quadrature component of reference supply currents is computed using a second PI controller over the amplitude of supply voltage $\left(\mathrm{V}_{\mathrm{tm}}\right)$ and its reference value $\left(\mathrm{V}_{\mathrm{tmr}}\right)$

$$
\mathbf{i}_{\text {spqr(n) }}=\mathbf{I}_{\mathbf{s p q r}(\mathbf{n}-\mathbf{1})}+\mathbf{K}_{\mathrm{pq}}\left\{\mathbf{V}_{\mathrm{ac}(\mathbf{n})}-\mathbf{V}_{\mathrm{ac}(\mathbf{n}-\mathbf{1})}\right\}+\mathbf{K}_{\mathrm{iq}} \mathbf{V}_{\mathrm{ac}(\mathbf{n})}
$$

Where $V_{a c(n)}=V_{t m r}-V_{t m(n)}$ denotes the error in $V_{t m n r}$ and computed value $V_{t m n r}$ form Equation (3) and $\mathrm{K}_{\mathrm{pq}}$ and $\mathrm{K}_{\mathrm{iq}}$ are the proportional and integral gains of the second PI controller.

The quadrature unit current vectors $\mathbf{w}_{\mathbf{a}}, \mathbf{w}_{\mathbf{b}}, \mathbf{w}_{\mathbf{c}}$ are derived from in-phase unit current vectors $\mathbf{u}_{\mathbf{a}}, \mathbf{u}_{\mathbf{b}}, \mathbf{u}_{\mathbf{c}}$ as

$$
\begin{gathered}
\mathbf{w}_{\mathrm{a}}=\left\{-\mathbf{u}_{\mathrm{b}}+\mathbf{u}_{\mathrm{c}}\right\} /\left\{\left(3^{1 / 2}\right)\right\} \\
\mathbf{w}_{\mathbf{b}}=\left\{-\mathbf{u}_{\mathbf{a}}(3)^{1 / 2}+\mathbf{u}_{\mathrm{b}}-\mathbf{u}_{\mathbf{c}}\right\} /\left\{2\left(3^{1 / 2}\right)\right\} \\
\mathbf{w}_{\mathbf{c}}=\left\{-\mathbf{u}_{\mathbf{a}}(3)^{1 / 2}+\mathbf{u}_{\mathrm{b}}-\mathbf{u}_{\mathbf{c}}\right\} /\left\{2\left(3^{1 / 2}\right)\right\}
\end{gathered}
$$

Three-phase quadrature components of the reference supply currents $\left(i_{\text {saqr }}, i_{\text {sbqr }}\right.$, and $i_{\text {scqr }}$ ) are computed using the output of second PI controller ( $\left.i_{\text {spqr }}\right)$ and quadrature unit current vectors $\left(w_{a}, w_{b}\right.$, andw $w_{c}$ ) as

$$
i_{\text {saqr }}=I_{\text {spqr }} \mathbf{W}_{\mathbf{a}^{\prime}} \mathbf{i}_{\text {sbqr }}=I_{\text {spqr }} \mathbf{W}_{\mathbf{b}^{\prime}} \mathbf{i}_{\text {scqr }}=I_{\text {spqr }} \mathbf{W}_{c}
$$

(iii) Computation of total reference supply currents

Three-phase instantaneous reference supply currents $\left(i_{s a r}, i_{s b r}\right.$, and $\left.i_{s c r},\right)$ are computed by adding inphase $\left(i_{\text {sadr }}, i_{\text {sbdr }}\right.$, and $i_{\text {scdr }}$ ) and quadrature components of supply currents $\left(i_{\text {saqr }}, i_{\text {sbqr }}\right.$, and $\left.i_{\text {scqr }},\right)$ as

$$
i_{\text {sar }}=i_{\text {sadr }}+i_{\text {saqr }}, i_{\text {sbr }}=i_{\text {sbdr }}+i_{\text {sbqr }}, i_{\text {scr }}=i_{\text {scdr }}+i_{\text {scqr }}
$$

A relay based current regulator with logic circuit is employed over the reference $\left(i_{\text {sar }}, i_{s b r}\right.$, and $i_{s c r}$, and sensed supply currents $\left(i_{s a}, i_{s b}\right.$, and $i_{s c}$ ) to generate gating pulses for IGBTs of DSTATCOM.

\section{SIMULINK MODEL OF UNCOMPENSATED LINE WITH LINEAR/NON LINEAR} LOAD

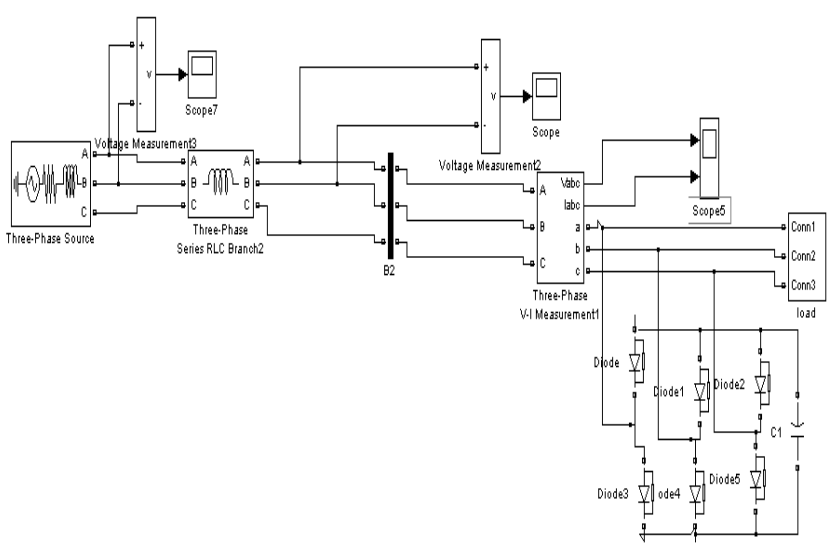

Simulink Model 


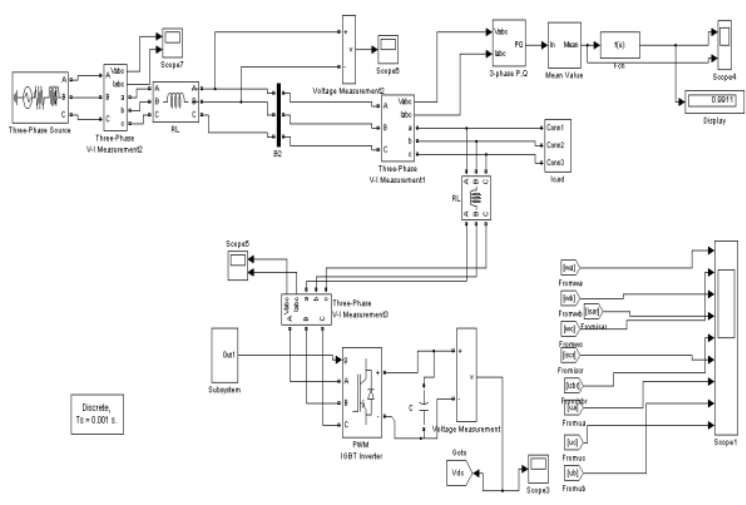

Power Circuit for Compensated line

\section{Result}

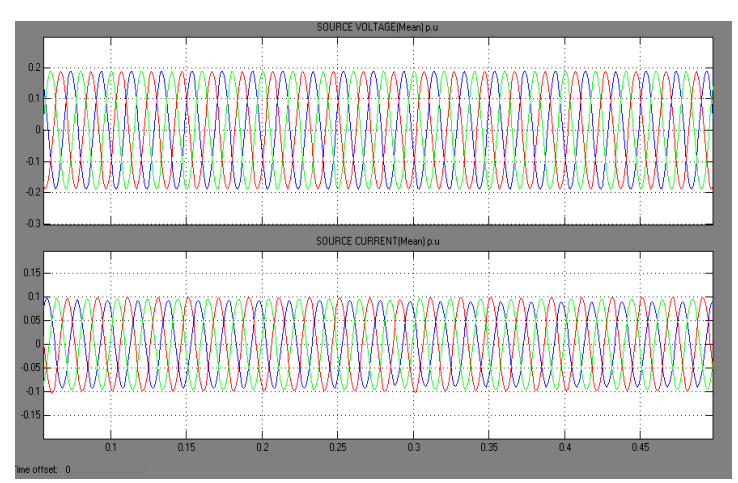

Voltage and Current across Source

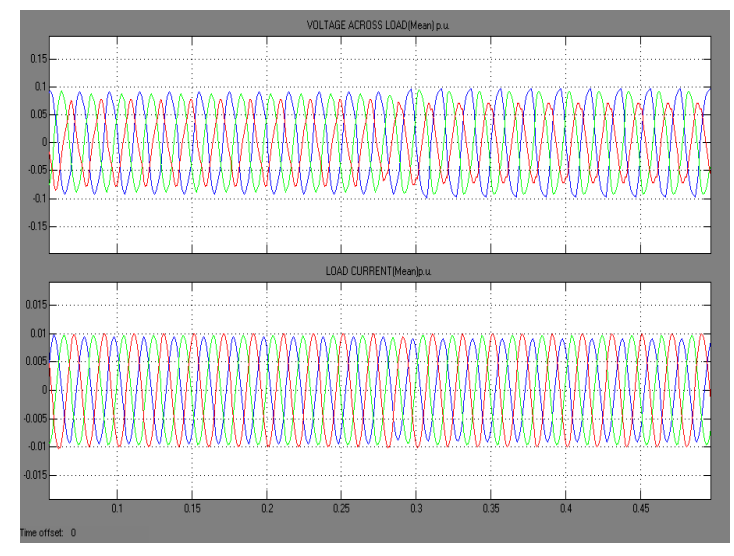

VOLTAGE AND CURRENT ACROSS LOAD

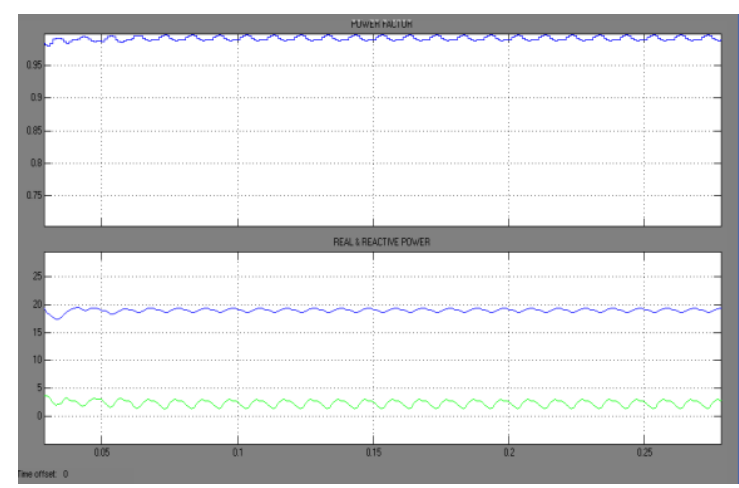

POWER FACTOR, REAL AND REACTIVE POWER

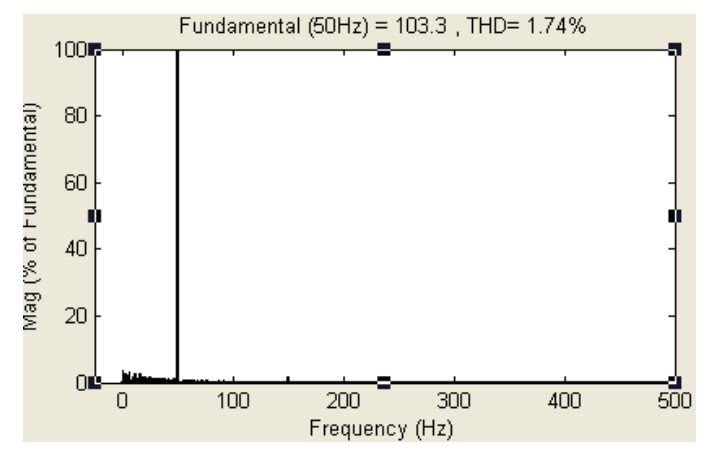

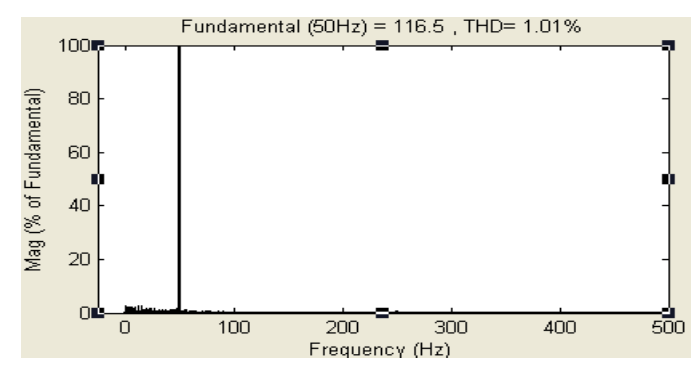

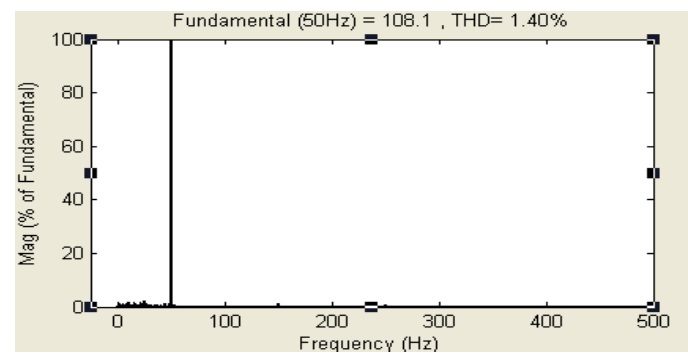

FFT ANALYSIS OF LOAD CURRENT: ILA, ILB, ILC 


\section{CONCLUSION}

The DSTATCOM control algorithm is suitably applied to the controller circuit interfaced with the current regulator $\&$ it is observed to be capable of correcting power factor \& mitigate harmonics. The same model with this current regulator can also be used for voltage regulation. The control algorithm of DSTATCOM has an inherent property to provide a self-supporting DC bus of DSTATCOM. Thus, it is concluded that DSTATCOM controller is very effective in supplying quality power supply at consumer end. It has the ability to replace conventional compensators like SVC in coming future and improve power quality at the distribution level.

\section{REFERENCES}

[1] Bhim Singh, Alka Adya, A.P. Mittal and J.R.P. Gupta "Modeling of DSTATCOM for distribution system" Int. J. Energy Technology and Policy, Vol. 4, Nos. 1/2, 2006,

[2] B. Singh, A. Adya, J. Gupta, "Power Quality Enhancement with DSTATCOM for Small Isolated Alternator feeding Distribution System" Power Electronics And Drive Systems 2005, (PEDS 2005), Vol1., 16-18 Jan, Pages: 274-279

[3] N. G. Hingorani and L. Gyugyi. Understanding FACTS: Concepts andTechnology of Flexible AC Transmission Systems, IEEE Press, 2000, pp. 135-143.

[4] Giroux, P., Sybille, G. and Le-Huy, H. (2001) 'Modeling and simulation of a distribution STATCOM using Simulink's power system block set', Proceedings of IECON'01 27 $7^{\text {th }}$ Annual Conference of IEEE Industrial Electronics Society, Vol. 2, pp.990-994.

[5] K. Anuradha, B. P. Muni, A. D. RajKumar, K.Balaji. "Novel Control Strategy for Cascaded

H- Bridge Converter based DSTATCOM." First International Conference on Industrial \& and Information System, ICIIS 2006, $8-11$. August 2006, Sri Lanka.

[6] Miller, T.J.E. (1982) Reactive Power Control in Electric Systems,Toronto, Ontario, Canada:Wiley 